\title{
Communication for Sustainable Rural and Agricultural Development in Benue State, Nigeria
}

\author{
A. I. Age (Corresponding author), C. P. O. Obinne \& T. S. Demenongu \\ Department of Agricultural Extension and Communication \\ University of Agriculture, Makurdi, Nigeria \\ E-mail: akosoiorbee@yahoo.com
}

$\begin{array}{lr}\text { Received: November 17, } 2011 & \text { Accepted: January 7, } 2012 \quad \text { Published: February 1, } 2012 \\ \text { doi:10.5539/sar.v1n1p118 } & \text { URL: http://dx.doi.org/10.5539/sar.v1n1p118 }\end{array}$

\begin{abstract}
This discourse discusses communication as a potent sociological tool for rural and agricultural development. It demystifies the concepts of communication, rural and agricultural development. It high-lights principles of communication, types of communication, communication barriers and the role of communication in a holistic and sustainable rural and agricultural development in Benue State, Nigeria. The epilogue concludes by noting that as long as there is continued imbalance in the diffusion of agricultural information and wrongful targeting of information, the possibility of harnessing the full potentials of our rural populace towards attaining sustainable and holistic national, rural and agricultural development will remain problematic and in a limbo and another political snafu. It is recommended that segmentation of the target audience based on needs, interested agro-ecological areas should be adopted by senders of agricultural messages; and decentralization of radio, and television broadcasting in local languages should be encouraged and underscored.
\end{abstract}

Keywords: Communication, Sustainable, Rural, Agricultural Development

\section{Introduction}

It is becoming increasingly apparent worldwide that development does not end in economics (industry) and that there can be no national development without rural and agricultural development. The new paradigm underscores local definition of developmental needs, which permits the inclusion of non-economic or non-industrial indices such as question of quality of life, equity and social participation (Okonkwor, 1987). The major issue in contention here is what aspect of development should greater emphasis be placed on? Should it be on increased agricultural productivity, better health and social conditions or development of human resources? According to Okonkwor (1987), more attention should be paid to development of endogenous skills and self-reliance. Understood this way, development involves more than modernization or urbanization. It rather evolves into a comprehensive phenomenon that comprises improvement in the totality of a people's life.

The cardinal objective of economic development upon which national development is predicated is the improvement of man himself (Okonkwo, 1987) the assumption here is that once you develop human resources, you have succeeded in creating an enabling environment for a holistic national development. To achieve this laudable objective, we must start with sensitization and mobilization of human resources towards acquisition of knowledge, skills and desired attitudinal changes. This is where communication should come in to sensitize, mobilize, persuade, engender and sustain people's interest with a view to adopting new ideas, practices or technologies that are likely to bring about holistic improvement in their well-being. What communication needs to do in this perspective is to provide an auspicious climate for rural and agricultural development which are sine qua non for a holistic and sustainable national development generally.

\subsection{The Concept of Communication}

Every social system consists of animate creatures that interact among themselves in their quest to survive in their social environment. Every living creature communicates. As human beings, we communicate with the whole of our body. In fact, every part of human body communicates something to others. The whole of human environment is surrounded by messages, some of which are purveyed intentionally and are consciously received and acted upon. A lot of human messages get lost en route. Most of our human problems can be traced in part to 
poor communication of messages. Human communication is necessary for the survival and growth of any society.

What then is communication?

According to Udall and Udall (1979), communication is a process by which one person (or group) shares and imparts information to another person (or group) so that both people (or group) clearly understand one another. It can, also be defined as a dynamic and cyclical process by which a message or information is initiated or conceived by a source (or sender) who decodes and purveys it through certain channels to a receiver who decodes the message and, consequently, shows some effect and acts upon it by giving feed back to the sender that it has been received and understood.

Ewhrudjakpor (1989) defined communication simply as a dynamic process of sharing information between individuals. Adebayo (1997) conceptualized communication as a process of information flow by which ideas are transferred from a source to a receiver with the intent to change his/her knowledge, attitude and/or skills. Thus, for each act of communication, to Laswell model (1948), we must attempt to seek answers to the following questions:

(1) Who? (source)

(2) Says what? (message)

(3) Through what means (channel)

(4) To whom? (Receiver) and

(5) With what effect (change in the receiver's behaviour)

Communication is a key process in information dissemination in agriculture. The development of agriculture requires, among others, a timely and systematic transmission of useful and relevant agricultural information from the technology generation system (source) via various communication changes to the intended audience (receiver). It is expected that the client's changes in behaviour as a result of the message received (effect) be passed back to the source (feedback) for the communication process to be complete (Adebayo, 1997).

Age (2009) defined communication as a process in which the participants create and share information with one another in order to reach a mutual understanding. In this process, emphasis is on interactive process of information sharing overtime to the ways in which participants interpret and understand information.

\subsubsection{The Major Elements of Communication}

The major elements of communication include the following:

\section{(1) Source or sender}

This refers to an individual or group of individuals or an institution or agency that initiates a communication scenario. It could be the research institute or extension agency or even an individual change agent wishing to purvey relevant agricultural message to the farmers. As a purveyor of innovations, the source is expected to be knowledgeable in the subject matter. To ensure up to dateness, the source is supposed to be trained on a regular basis so that he can acquire the necessary methodologies of communication.

\section{(2) Message}

This refers to the agricultural information or idea or technology that the source whishes to purvey to the end-users and, of course, compatible with the existing practices, societal norms, belief and culture of the society before they can be widely adopted and/or confirmed. Relevance of message, connotes being technically feasible, economically affordable and socially acceptable by the generality of the people in the society.

Messages take several forms made up of several physical elements, which may be words with symbolic meaning or just ideas encoded into symbols to which meaning can be attached. Encoding connotes the changing of meanings into symbols or forms (messages) appropriate for dissemination to the receiver. When a source initiates communication scenario after conceiving what has to be communicated, he encodes or changes the meanings of the conceived message into symbols or simple understandable forms and, then, sends this message through a channel to the receiver. When the receiver receives the message, he decodes it, (that is, attaches meanings to the symbolic message) and then develops an idea of what the message is all about in his/her mind. Decoding connotes the translation of received message into interpreted meanings. As soon as the receiver decodes a message, he/she reacts to the massage by sending feedback to the source, who now becomes the receiver of feedback message. 


\section{(3) Channels}

This connotes the means through which a message travels from the source to the receiver and vice versa. Communication channels can be categorized into:

(i) Physical channels, which involve direct contact. For example, visits, seminars, workshops, exhibitions, advisory village meetings, agricultural shows etc.

(ii) Non physical channels such as T.V, radio, phone calls, newspapers, magazines, and other print media channels.

(iii) Technical channels which could be physical or non-physical.

(iv) Human discipline channel, for example, dresses put on by professionals such as medical doctors, nurses, army officers, etc depict their professions

(v) Token of communication channels, which are channels in between physicals and non-physical channels. For instance, signals, gestures, idols at the shrines and other symbols.

Besides, other channels of communication are life drama such as theatre groups, audio visuals, print media, folk media such as traditional songs, dances, talking drums, village criers etc. In the communication of agricultural messages to the end-users, it is advisable to use a variety of communication channels. This is because the more senses are employed in the communication process, the most likely that communication messages will be easily understood.

(4) Receiver

A receiver is the target audience of communication, who decodes message symbols into interpreted meanings. According to Adebayo (1997), modern communication theory holds that meanings are not messages, rather they are convert responses contained within the human organism. They are learned and personal, thus, people who have similar meanings can communicate more effectively. In agricultural extension communication, it is expected that common meanings should be established between the source and the receiver.

Usually, farmers' farm families and farming communities are regarded as the end-users of agricultural extension messages. However, any member of agricultural research institutes, or extension agency, as well as policy makers who have acted as a source could, also, be a receiver, particularly of feedback communication. In order to ensure effective communication of agricultural messages to the target audience, it is expected that the communication message should be related to the goals and such messages should be designed for a specific audience in mind. It is, also, expected that segmentation of the audience should be carried out before directing such messages to them. This is because not all farmers are the specific target audience of certain agricultural messages. So, when we direct messages to all farmers without considering their needs or interest in their various agro-ecological areas, such messages will not reach their target audience. There is need, therefore, to segment or stratify the entire population based on their agro-ecological zones, needs and interests before directing agricultural messages to the target audience.

(5) Effect

Communication effect connotes the phonotypical or overt change in the receivers' behaviour, which occurs as a result of the message received. This change in behaviour could be in terms of knowledge, skills, attitude or habits. Effective communication takes place if it results in the intended behaviour of the receiver, or audience.

(6) Feedback

This refers to a response from the receiver to the source. By the concept of feedback communication, the source is, thus, viewed as a receiver. Feedback is an indispensable device that can be harnessed to measure the success or failure of communication. In fact, sending a message alone without finding out the extent of its diffusion among members of a social system and of course the effect of such a message will be a useless exercise. Effective communication can occur if and only if there is communication with feedback.

Feedback assures the source that his message has been received, understood correctly, interpreted (decoded) and acted upon. Through feedback, the source knows whether to continue or end his communication and whether or not to stop and modify his language and mode of presentation. Thus, feedback helps to guide the source through the murky waters and difficult terrain of interpersonal communication. To ignore the place of feedback in any communication scenario is to weaken communication effectiveness. 


\section{(7) Noise}

In extension parlance, noise is any interference en route transmission and reception. In other words, it is a barrier that prevents a message from getting across to the intended audience. Noise may be of three broad categories (i) physical noise, (ii) psychological noise and (iii) linguistic noise. Physical noise comes from loud conversations, side talks at meetings, sound from workmen's tools and, of course, horns from moving vehicles. Psychological noise comes via poor mental attitudes or emotional stress. Linguistic noise refers to the communicators' inability to use the language of communication accurately and appropriately. Linguistic noise is sub-divided into semantic, grammatical and phonological noise. Semantic noise results from wrong choice of words, use of unfamiliar words or use of familiar words in unfamiliar ways. Grammatically, noise may result in the form of faulty sentence structure, misapplication of the rule of correct language use. Phonological noise occurs through poor pronunciation or words. Noise may, also, come by the way of poor spelling, poor writing or even a drop of ink water, which blurs whatever is written.

\subsubsection{Principles of communication}

The basic principles of agricultural extension communication include the following among others:

(1) Farmers need to be informed of what is happening around them. It is when one knows what is happening around him/her that he/she will be able to function properly in his/her environment. It has been found that when human beings are deprived of information around them, they tend to become dehumanized and completely ignorant of their environment. A popular adage says "no one is an island of knowledge". It, therefore, means that for an individual person to be able to function properly in his/her environment, he/she needs some forms of information.

(2) Communication message should be designed with specific objectives in mind and should be directed to the target audience. Before starting or initiating any form of communication scenario, the source needs to determine the goals or objectives of his communication. What does he/she want to achieve at the end of his communication? The source also needs to know about the target audience of his communication. This entails knowing the socio-economic background of the audience in terms of their level of education, their level of income, occupation, social status, their needs, interests and their agro-ecological areas. It is only when audience analysis has been done by the communicator that he/she will be in a better position to segment the target audience with a view towards directing appropriate communication messages to them in order to meet their needs, interests and aspirations. There is no need directing all agricultural messages to the entire population because such broad-based messages do not reach their destinations.

(3) Message content should suit the needs and interest of the target audience, not the sponsor. In order to achieve effective communication and make positive contribution to agricultural development, the message content of communication should suit farmers' farm situation as well as their socio-cultural milieu in which they operate. The popular adage that 'he who pays the piper dictates the tune' should be ignored.

(4) There is need to use a multi-media channels of communication in purveying agricultural messages to farmers. This is because different channels appeal to different senses. According to Adebayo (1997), human senses often reinforce each other in the acquisition of knowledge and skills. Therefore, when two or more communication channels are used to share information with the audience, the end-users tend to understand the message much better than if only one channel was used.

(5) The communicator should empathize with the receivers in order to ensure effective communication. He should act at the level of the audience.

(6) The source should always be homophilious with the receivers in order to ensure effective communication.

\subsubsection{Types of communication}

Basically, there are three types of communication, namely:

(i) Intrapersonal communication, (ii) Interpersonal communication and (iii) Mass communication.

\section{i. Intrapersonal communication}

This refers to communication with an individual through his/her senses, which enables him/her to take decisions. It is more or less an electrochemical action of the body taking place within ourselves and it is sometimes referred to as soliloquizing. In fact, intrapersonal communication is the basis of all other forms of human communication. Without an effective system of intrapersonal communication, an organism will not be able to function properly in its environment or to be open to external forms of communication. It is this type of communication that allows an individual to take decisions based on information received through his/her senses. For example, when an 
individual is watching, say, football match on T.V. or film, his eyes and ears receive information and communicate it to his brain. If what he sees and hears is interesting to him, his intrapersonal communication system will indicate that and he will continue watching that football match. If he finds it uninteresting, his brain will send a message to his muscles that will result to taking a decision either to put off the TV or to leave his room and go to the market. Another instance is this, suppose one is busy enjoying one's pounded yam with goat meat which is a delicacy in one's locality and somebody calls him from outside and just as he is about to stand up to open the door for his visitor, one's GSM hand set rings. One finds it difficult to decide whether to answer the call from outside or that of the GSM hand set. One is at a crossroad. It is one's intrapersonal communication system that will help him at this point to take decision.

If we apply these examples to Bittner's Communication Model, we than see that his eyes and ears become the sources or senders of electrochemical impulses (message) through his central nervous system, which is his medium of communication. His brain becomes the receiver of these impulses, which transmits additional electrochemical impulses in the form of feedback to his muscles, producing such physical activities as putting off the TV or answering the phone call.

From the second example above, we can see that the GSM phone call interfered in the intrapersonal communication process and, therefore, can be regarded as noise, because it encumbered decision-making process of that individual.

\section{ii. Interpersonal Communication}

Interpersonal communication, according to Soola (1993), is a two-way, two-some or dyadic communication. It is a face-to-face encounter or transactional exchange of information. This type of communication is the basic means of effecting behavioural change. It incorporates psychological processes (perception, learning and motivation) as well as language. Of relevance to interpersonal communication is listening sensitivity and non-verbal communication.

As people interact in interpersonal context, they exchange ideas, attitudes emotions and opinions. Interpersonal communication is an interaction of a conversational nature.

\subsubsection{Ways of improving interpersonal communication with farmers}

There are a good number of ways improving interpersonal communication with farmers. According to Obinne (1992), experts have suggested the use of traditional mass media (folk media) as credible channels of reaching the most disadvantaged audience the rural poor.

According to Soola (1993), one of the several ways in which effective interpersonal communication can be pursued, achieved and sustained is by appreciating the culture of the people. Knowing the culture of a participant in an interpersonal communication transaction serves as a significant predictor of the communication behaviour of the participant. In addition, such knowledge helps to determine the language choice that can be used for effective communication.

Another way of improving interpersonal communication is knowing the people or person involved in communication scenario. Much of our communication ab-initio is designed to provide us with information about the person and people with whom we are interacting interpersonally. Much of what goes on in the first few minutes of interpersonal communication between strangers is some form of information gathering on the part of each participant with a view to establishing a rapport, and establishing a rapport involves knowing each other. It is only when people know each other that they can communicate freely.

More so, there is need to shun dominance or control in communication and that is what is known in communication parlance as symmetrical relationship. In this kind of interpersonal communication, both participants should claim equality. Success in interpersonal communication/interaction will be better achieved better in a parallel communication relationship, in which each participant has an area of control. In an agricultural extension situation, while the extension worker is the purveyor of technical or specialized information, and should be allowed to exercise control in this area, the rural farmer is more knowledgeable about his day-to-day experiences, problems and indigenous farming practices.

Obinne (1992) stated that change agents should be homophilous in their dealing with farmers. That means that for effective interpersonal communication to take place, change agents should come down to the level of the farmers in terms of language, societal norms, beliefs or culture, level of knowledge and even behaviour, all of which are supposed to be taken into consideration. The change agent should not be boastful or arrogant but calm and humble, even to the extent of living among the clientele in the rural areas. 
Generally, extension workers must show empathy and they should be able to understand and appreciate their clientele (Obinne, 1992). Empathizing with farmers helps to establish more rapport with farmers that is sine qua non for improving interpersonal communication with them. Change agents should always use simple and local languages during discussion with farmers and should only discuss matters that are of interest to the farmers without forcing their opinions on them.

Finally, interpersonal communication can be improved with farmers by recognizing the place of non-verbal communication in human communication interaction. Soola (1993) stated that one major barrier to interpersonal communication is to underplay the crucial significance of non-verbal communication. It is not often realized that, as human beings, everything about us communicates something to other people. Thus, our hairstyle, the dress we wear and our manner of wearing it, our sitting and standing postures, our facial expressions, the movement of our whole body or part thereof, our silence, all communicate without our uttering a word. Non-verbal communication transmits feelings, emotions, likings, personal meanings and preferences.

The implication of this is that action speaks louder than words. Non-verbal communication may, therefore, either be a liability (a barrier) or an asset to effective interpersonal communication, depending on whether or not we recognize its potency and exploit it with utmost care.

\section{iii. Mass Communication}

Mass communication involves sending messages through a mass medium to a large number of people. For mass communication to exist, we need an intermediate transmitter of information called a mass medium. A lot of mass media are used in mass communication such as newspapers, magazines, film, radio, television, internet, books or combination of these. Mass communication messages are directed at a group of people via mass medium. Books were the first mass media, followed by newspapers, magazines, film, radio, television and now the advent of the World Wide Web (www).

The mass media channels have distinct operational features. Some of these include;

(i) Mass medium, (ii) Impersonal (iii) Gate keeper (iv) Delayed feedback (v) Hardware and software.

\subsubsection{Communication Barriers}

Communication barriers refer to constraints or problems that encumber free flow of information from the source to the receiver. Some of these problems include:

Noise, incorrect message content, cognitive dissonance, information overload/fatigue, material inputs, wavering attention and, information selectivity.

\section{Noise}

This refers to anything that interferes or distorts effective communication. Noise could be physical, psychological and linguistic in nature as earlier discussed. According to Adebayo (1997), one way of reducing noise in the message is to increase redundancy through writing the same message in different forms but with similar meaning. For instance, "wash the fruits very well" or "ensure that all the dirts are removed from each fruit". Both of these imply a thorough cleansing of the fruits. Noise can be minimized by controlling physical, psychological and linguistic factors. Physical noise can best be controlled by distancing oneself from loud sound; observing absolute silence and satisfaction of physiological needs to prevent wavering of attention, while psychological and linguistic noise can best be controlled by controlling emotional stress and correct use of grammatical rules, words and pronunciation of words, respectively.

\section{Incorrect Message Content}

Change agents who possess mastery of the subject matter as well as use appropriate teaching methods and visual aids can easily pass across their messages to the target audience. The reverse is, also, the case, especially when incorrect and irrelevant messages are disseminated by incompetent change agents to the end-users. Such change agents may lose credibility, especially if it is found out that their information is false. Even when correct information is passed on, the method of presentation may either make or mar the success of communication.

\section{Cognitive Dissonance}

This connotes negative knowledge attribute of farmers. In other words, it refers to knowledge which is inconsistent or incompatible with a farmer's interest, attitude beliefs or culture. If a change agent fails to conduct audience analysis but goes ahead to pass on information that is not compatible with societal norms or culture or beliefs, such information may not be accepted by farmers even if it has some relative advantages. 


\section{Ethnocentrism}

This refers to a tendency whereby some people see their culture as being superior to other cultures, to such an extent that any information disseminated to them by people from other cultures may be relegated to the background and, consequently, rejected subjectively. For example, a change agent from Zamfara State wishing to disseminate certain information to Ibo farmers in Imo State may not be allowed on the ground that he is coming to Islamize their state and/or introduce sharias in their state. This attitude affects communication of agricultural innovations to the end users.

\section{Information Overload/Fatigue}

Information overload means passing excess information than the carrying capacity of the receiver. This leads to the befuddlement or confusion and information fatigue. In communicating agricultural messages to farmers, there is need to first of all carryout audience analysis with a view to knowing the socio-economic characteristics of the farmers. This enables one to design messages according to their educational background and taking into consideration individual differences. Agricultural messages should, therefore, be passed on to the farmers in a piece meal and at their own pace.

\section{Delayed Feedback/lack of Feedback}

The use of gatekeepers in mass communication may cause delayed feedback and this affects timely passage of messages to farmers. In some cases, there may be no feedback at all. This is capable of causing misunderstanding which can impair communication effectiveness.

\section{Feed Forward}

This connotes either positive or negative information about the receiver, which the source has prior to initiating communication. If the source has false information about the receiver, his communication will founder even before he commences. This is true because false conception will serve as noise that is capable of distorting information or black-mailing the receiver, thus, dainting his credibility.

\section{Shortage of Material Inputs.}

Diffusion of an innovation into any social system is one side of a psychological coin and ability to adopt such an innovation is another side. Most of the farmers lack the wherewithal (capital or labour) to practice introduced innovations. In most developing countries, experience has shown that resource-rich farmers tend to adopt new farming practices much more quickly than the resource-poor farmers (Adebayo, 1997). It was earlier thought that it is the mental characteristics of the farmers that make them to adopt an innovation. It has been found, however, that most farmers will adopt new ideas only if they have the resources, and are not hampered by physical, social or organizational constraints (Adebayo, 1997).

\section{Wavering Attention}

A farmer's physiological needs may stand between him and adoption or rejection of an innovation, irrespective of its high degree of relative advantage. In other words, a farmer's attention may waver in a communication scenario simply because some of his basic or physiological needs are not satisfied. For instance, a hungry or thirsty farmer may not be attentive during method demonstration and as such may not be able to comprehend the message content or decode the message appropriately.

\section{Information Selectivity}

Farmers tend to be selective in their choice of communicated messages based on their compatibility with their existing practices, or societal norms, values or beliefs. So, when a well-thought out package of production recommendation is disseminated to them, they tend to select part of the message based on what they want to know.

\section{Homophily Versus Heterophily in Communication}

Homophily is the degree to which pairs of individuals who interact are similar in certain socio-economic attributes or characteristics such as level of education, occupation, beliefs, social status and so on. Effective communication takes place when a source-receiver pair is homophilous. The most effective change agents are those who are like their average clients on all variables with the exception of technical competence about the innovation promoted. The more nearly equal in social status, education and occupation people are, the more frequently they will interact among themselves. Age (2009) opined that communication between source and receiver is likely to be when both of them share common meanings, attitudes, beliefs and of course mutual language. According to this scholar, social relations are much closer between individuals who resemble each 
other in socio-economic characteristics. This conceptual label, according to Obinne (1992), is one of the most obvious and fundamental principles of human communication, which implies that the transfer of ideas most frequently occurs between a source and a receiver who are alike (similar/homophilous)

Heterophily, on the other hand, refers to the degree to which pairs of individuals who interact are dissimilar or different in certain socio-economic attributes such as education, occupation, social status, and culture or beliefs etc. Some studies have shown that heterophilous communication leads to message distortion (ineffective communication). According to Obinne (1992), one major problem in communication of innovations is that the source is usually quite heterophilous to the receiver. According to him, some degree of heterophily is necessary because the source is expected to be more technically competent than the receiver. Generally, receivers such as smallholder farmers often seek sources that are slightly more technically competent about innovations then themselves.

In effect, most individuals would prefer to interact with people who are more or less on the part of technical propinquity. It has been found that interaction with people who are hetereophilous involves greater efforts to make communication effective. In other words, heterophilic interaction is likely to result in cognitive dissonance because the receiving unit is exposed to messages that are likely to be inconsistent with his existing beliefs, an uncomfortable psychological condition.

Heterolphilous individuals who have high empathy are, in a social psychological sense, really homophilous. Empathy connotes the ability of a person to project himself into the role of another person. If, for example, a source observes how the receiver feels,and sympathizes with him, it is possible to design a message to suit the needs, interest and condition of the receiver.

In conclusion, it should be noted that communication between heterophilous source-receiver pair is less effective than between a homophilous pair. However, complete homophily does not exist in any communication scenario, given that the source and the receiver are usually dissimilar, at least in some aspects.

\section{Literature Review}

\subsection{Concept of Agricultural Communication}

Basically, an understanding of extension communication systems in a complex chain of interaction is a major determinant of the potential success of a scientist in a research institute (Siyanbola, 1996). Sustainable development in the agricultural sector is dependent on generation of appropriate technologies and creation of effective communication strategy for dissemination of recommended techniques to end-users (Dimelu and Anyanwu, 2005).

Communication is conceptualized as a process of information flow by which ideas are transferred from a source to a receiver with the intent to change his /her knowledge, attitude and /or skill (Adebayo, 1997). It is the key process in information dissemination in agriculture. The dissemination of information from point of development to the point ultimate use is an important concept in agriculture extension delivery. For technology to be relevant, its existence must be known -a condition, which presupposes communication.

Adebayo (1997) explained that, adoption and transfer would hardly take place unless the farmers (receiver) attaches the correct and intended meaning to the technology (message) and also responds favourably as intended by the extension agent (source). It is necessary to bridge the gap between available knowledge on improved technologies and actual practices, effective information delivery since which is the missing link between the research - extension interface, and practical application of the results by the peasant farmers (Entsua-Mensail, 1993).

Agricultural communication as a branch of study in agriculture, deals with the planning and management of agricultural information and methods of effectively communicating agricultural technology in order to bring about desired changes in farmers' behaviour and their farming practices for improved living. In the context of agricultural extension services, agricultural communication is a process by which extension workers exchange attitudes, share knowledge and skills on behalf of their organizations with farm families through a medium in ways that each gain an understanding and use of the message(Agbamu,2006).Agricultural communication enhance a two-way flow of information in which farmers share information among themselves or an agricultural organization delivers message to farmers in such a way that both farmers, or the agricultural organization and the farmers establish commonality in meaning over the shared information and messages delivered with the intention of improving the knowledge, attitude and skills of farmers in given innovations. 


\subsection{The Concept of Development}

Development is a multifaceted and normative concept meaning different things to different people (Adebayo, 1997). Development is simply a rapid and sustained rise in real output per head and an attendant change in technological, economic and demographic characteristics in a society. Yahaya (2003) described development as a trend in the technologies, organizations, activities and values of a society. According to this Scholar, the indices for measuring development are economic growth, cultural and racial prejudices, equity in income, egalitarianism (personal freedom), technology and ecology.

Majority of economists, psychologists, sociologists and political scientists have, at one time or the other focused their attention on the colossal inequalities among the world's nations (Okonkwor, 1987). According to him, the gross national product (GNP) and literacy rate are often used as indices for measuring national development. The tendency to notice a correlation between high per capita income and high literacy rate is then taken as the basis for national development. Fapohunda (1979) stated that the economic development of a country depends on the quantity and quality of its resources, the state of technology and the efficient deployment of resources in both the production and consumption processes.

The import of all these definitions is the strong emphasis on a change from an unfavourable condition to the better in both socio-economic and cultural conditions of individuals cum the entire society.

Rural development, on the other hand, can be conceptualized as a strategy designed to improve the socio-economic life of the rural poor. It involves extending the benefits of development to the poorest among those who seek a livelihood in the rural areas. Rural development includes the provision of social, physical, and institutional infrastructural facilities (such as health facilities, pipe bone water, education, electricity power supply and a host of other continuums) to a special group of people. The group includes small-scale farmers, tenants and the landless (Abe, 1991).

The rural area is the main place of abode of about 80 per cent of peasant Nigerians who subsists on agricultural production and marketing. In order to bring about national development, the rural areas should be developed. Since rural people subsist on agriculture, rural development endeavours should be shifted to agricultural development, which is the bedrock for national development.

Famoriyo (1985) defined agricultural development as a process of transforming agriculture from a predominantly subsistence level to an economy dominated by investment and market-oriented agriculture. According to Okonkwor (1987), agricultural development is a process of change not fully from the traditional and subsistence mode to more productive and commercialized enterprises but also the transformation of the people who engage in it. According to him, agricultural development depends on the availability of basic primary factors such as effective marketing system, adequate supply of farm inputs of high quality, attractive price policies, subsides, tax reliefs, efficient transportation system and continuous and effective research-extension farmer linkages.

Rural development, therefore, cannot take place without serious agricultural development. However, for agricultural development to result in a self-sustaining improvement in farming, the knowledge, skills and attitudes of the farmers must keep increasing and changing. This is where the role of the media must be recognized in the overall planning and execution of rural, agricultural and national development programmes.

\subsection{The Role of Communication in National Development}

Mass media channels have some distinctive operational features such as hardware, soft ware, professional managers and "gatekeepers". According to Yahaya (2003), "gatekeepers" apply to institutions wherein both people and technology interact to control the events that determine the transfer of information for the source to the receiver. Information passed by gatekeepers may be considered reliable because such messages might have compiled and edited by a team of experts such as reporters, editors, cameramen, engineers, writers etc. In this respect, gatekeepers are shapers of opinions in communication and media industry.

Mass media institutions such as newspapers, magazines, books, motion pictures, radio, TVs, internet and sound recording help in the generation and dissemination of messages that are of immediate needs to the general public. Besides, these media institutions contribute greatly towards the growth and development of knowledge as well as its preservation through documentation. Through this, researchers can gather enough research data and finally come out with workable solutions needed to solve human problems that hitherto had formed a cog in the wheel of national development.

Mass media help in sensitization of all stakeholders and beneficiaries of agricultural, rural and the overall national development programmes. Mass media channel such as radio and television are used to create 
awareness in people about newly introduced programmes, projects or farming technologies with a view to adopting them.

The mass media try to persuade the beneficiaries or target audience in order to engender or kindle interest in the minds of the target audience so that they can develop favourable attitudinal changes needed for adoption of innovations or programmes.

Any development programme that is bereft of realistic objectives and has not taken into consideration social needs and interests is bound to founder. It is the responsibility of mass media to direct such developmental objectives to the target population and to ensure that such a programme meets the needs and interest of the famine.

Yahaya (2003) enumerated other functions or roles of the mass media to national development, thus:

i. Surveillance function: This is what makes the media "the society's watch dog, "because they facilitate the spread of political messages (tragedies) and shaping of information about events happening around the world.

ii. Interpretation function: the mass media gatekeepers try to translate messages in local and simple languages that can easily be understood by the general public to prevent distortion of information. According to Ewhrudjakpor (1989), a common language plays a vital role in communication of all the forms of social interaction. The language people speak is the most compelling and enduring source of cultural identity. Cultural identities and differences tend to follow linguistic lines. In fact, Belgium and Nigeria have been encountering continual problems of maintaining national unity because linguistic differences reinforce and accentuate cultural differences.

iii. Cultural transmission function: mass media help to give further information and clues about the society and, also, help in socialization process.

iv. Entertainment function: Mass media help in creating joy and excitement outlets, for many people.

v. Propaganda function: Mass media can be used to brain-wash people and to popularize specific issues of interest to political leaders.

vi. Commercial function: Mass media can be used for advertisement and income generation for different business outfits.

\section{Negative Influences of the Mass Media}

In spite of the numerous roles mass media have been playing to bring about national development in Nigeria, certain snags seem to influence mass media negatively.

First, majority of psychologists believe that viewing violent and immoral T.V or video programmes increases interpersonal aggression and unethical demeanours among young children.

Second, exposure to mass media programmes (T.V. or radio drama) can lead to acculturation, which is detrimental to nurturing and sustenance of African's culture. A closer look at how our educated ladies dress these days is a clear example of adulteration of African culture, which mass media have imported. This seems to be one of the imperialistic weapons the western nations are using now in their neo-imperialistic tendencies to enslave Africans indirectly. According to Ewhrudjakpor (1989), the acculturation of African countries is mainly through aggressive importation of mass media products via satellite television. These mass media expose individuals, social systems and the government to various programmes alien to our society. Good examples include the idea of gender inequality, influence on our dressing, education and even eating habits. All these lend themselves to influencing our beliefs, attitudes and behaviours either negatively or positively. For instance, the television drama on female circumcision is one effective persuasive way of stopping female genital mutilation in Cross River State, thus getting rid of strongly imbedded traditional beliefs in certain parts of Nigeria.

\section{Methodology}

\subsection{The Study Area}

Benue State is situated in the middle Belt region of Nigeria. The state is situated in the Middle Belt region of Nigeria. It is located on Longitude $6^{\circ} 35^{\prime} \mathrm{E}$ to $10^{\circ} \mathrm{E}$ and Latitude $6^{\circ} 30^{\prime} \mathrm{N}$ to $8^{\circ} 10^{\prime} \mathrm{N}$.

The state shares common boundaries with Nasarawa State to the North, Cross River and Enugu States to the South, Kogi and Ebonyi States to the West and Taraba State to the East. The 2006 population census puts the total population of the state at 4,219,244 (NPC 2006). The land mass spans some $34,059,244 \mathrm{~km}^{2}$ of the guinea savannah vegetation belt with temperatures ranging between $25^{\circ} \mathrm{c}$ and $37^{\circ} \mathrm{c}$. 
The state has distinct wet and dry seasons. The wet season starts in April to October while the dry season starts in November to March. The dry season, also called harmattan is characterized by dry and dusty North Eastern Winds. The wet and rainy season, with the mean precipitation of $1500 \mathrm{~mm}$ has two peaks, May/June and August/September. Relative humidity during the wet season is high while during dry season is low.

Farming is the major occupation of the indigenes. Crops grown include yam, rice, sorghum, maize, millet, cassava, water yam, cocoyam, and sweet potato as well as tree crops such as citrus, mango, oil palm cashew and guava.

Administratively, the state is divided into 23 local government areas which are zoned into three senatorial zones; Zone A, B and C.

\section{Conclusion}

National development is the mission of all countries the world over and to attain this laudable objective, there is need to start this development at the grassroots by giving agricultural and rural development their rightful place in the scheme of things. One of the giant strides in this perspective is the development of human resources through appropriate use of mass media channels. As long as there is continued imbalance in the distribution and wrongful targeting of information, the possibility of harnessing the full potentials of our rural populace towards attaining national development will ever remain problematic and in limbo.

\section{Recommendations}

Mass media could be a veritable sociological tool that could be harnessed to breed national development only if all stakeholders of national development adopt the following workable strategies.

(1) Segmentation of the population in terms of needs and interest. That is to say, efforts should be made to stratify the target audience based on their developmental needs and interests or agro-ecological zones. When campaign messages are directed at the entire population at the same time without considering the needs and interest of various agricultural zones, then such messages may end up reaching nobody. For instance, a campaign about piggery farming will be of no value to Moslem communities, just like that for cattle farming will not interest people from rainforest zone, where there are a lot of tsetse flies and the entire area is too swampy. All rural farmers according to Okonkwor (1987), cannot constitute the target audience, hence there is need to first of all stratify the entire population based on needs and interest before directing campaign messages to them.

(2) There is need to relate message to the set objectives and then design messages or programmes for a particular target audience in mind. When messages are closely related to set objectives, designed with particular audience in mind and programmes are properly executed, the tendency is to achieve a successful campaign (Okonkwor, (1987).

(3) There is need to use a mixed media strategy. Traditional folk media can be integrated with modern conventional media.

(4) There is need to decentralize radio and television broadcasting using local languages; and

(5) Involvement of various social groups in video, radio and television programming and to highlight the various roles of media personnel, institutions and extensionists to avoid multiplicity of information or duplication of efforts.

\section{References}

Abe, H. A. (1991). Role of International Agencies in Rural Development: The case of UNICEF-Assisted Water and Sanitation Project, Paper Presented at workshop on improving the Management of Capability of Local Government in areas of Agriculture and Rural Development held at ARMNTO, Ilorin, 11-12 September, 25.

Adebayo, K. (1997). Communication in Agriculture, Greenlinks International Abeokuta, Nigeria, 102.

Age, A. I. (2010). Basic Agriculture for Universities in Nigeria. Larigraphic publishers, Jos. 217.

Dimelu, M. U. and Anyanwu, A. C. (2005). Importance of Radio - Rural forum (Listening Group) as an Extension Strategy in Nigeria. In: S.F. Adedoyin(ed) Structure and operation of Agricultural Extension in a Democratic and Deregulated Economy. Proceedings of the ninth Annual National Conference of the Agricultural Extension Society of Nigeria. $8^{\text {th }}-11^{\text {th }}$ March, 2004. 30-33.

Entsua-Mensail, C. (1993). Linking Research and Extension Services for sustainable food production in Ghana: Some options for achievement. Quarterly Bulletin of LAAKD, 40(4), 121-125. 
Ewhrudjakpor, C. (1989). Sociological Perspective of Human Communication In: Bittner, J.K. (ED). Mass Communication. An introduction $5^{\text {th }}$ ed. Prentice Hall, Engikewood Clifts, New Jersey, 250.

Famoriyo, S. (1985). A review of the changes in Agricultural and Rural Development strategies in Nigeria. In: Akin, F. (Ed.). Issues on Development. Proceedings of a Seminar held in Zaria, Nigeria, 21-21 January. Centre And Economic Research, A.B.U. Zaria. pp114

Fapohunda, E. R. (1979). Population and Manpower Development. In: Olaloku, F.A. (ed.) Structure of the Nigerian Economy. Macmillan Publishers, University of Lagos Press. 270.

Okonkwor, C. (1987). The Media in Agricultural Development Paper presented at the $23^{\text {rd }}$ Annual Conference of the Agricultural Society of Nigeria held at the University of Nigeria, Nsukka, August 31-September 3, 15.

Siyanbola, A. T. (1996). Essentials of Effective Communication between Research and Extension for Sustainable Agricultural Development in South-Western Nigeria. In: S.F. Adedoyin and J.O.Y. Aihousu (eds). Sustainable Development in Rural Nigeria Proceedings of the Eight Annual Conference of the Nigerian Rural Sociological Association, 263-269.

Yahaya, M. K. (2003). Development Communication Lessons From Change and Engineering Projects. Corporate Graphics Ltd. Ibadan, Nigeia. 240.

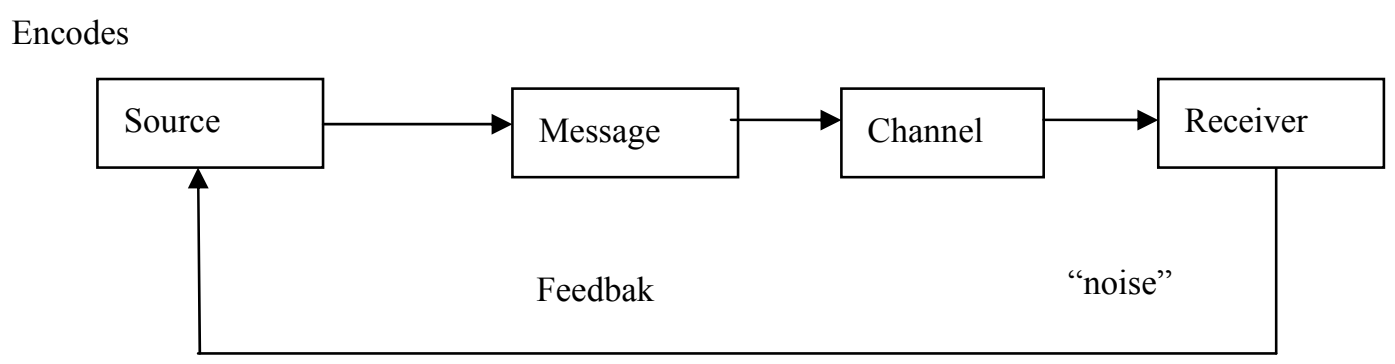

Figure 1. Communication with Feedback

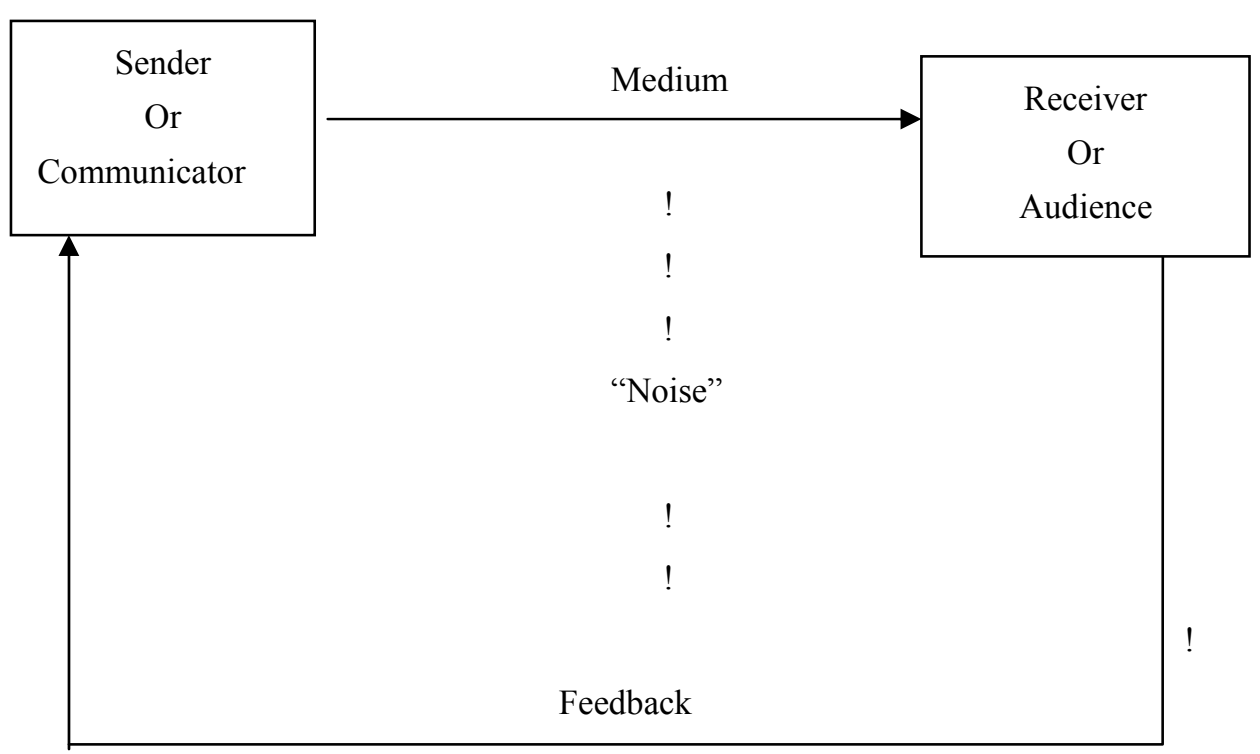

Figure 2. Bittner's Communication Model

Source: Bittner (1989) 